\title{
Da Filologia Cósmica
}

Julian Alexander Brzozowski

UFSC

\begin{abstract}
Resumo
Presenciamos, atualmente, algo de um momento crítico para o pensamento, que se expressa de maneira análoga em diversas áreas do conhecimento. $\mathrm{Na}$ filologia, é experienciada a exaustão de um predomínio do modelo mimético auerbachiano, conforme a noção do Real lacaniano toma conta da sensibilidade literária ocidental. Tal assunção levou o pensamento moderno a um paradigma mórbido da existência, expresso nos trabalhos de Heidegger, Lacan e Agamben, e numa posterior leitura contemporânea algo desbalanceada do paradigma biopolítico foucaultiano, "fazer viver e deixar morrer", que enxerga no encontro com a Coisa o fundamento e o horizonte da tanatopolítica. O presente ensaio visa propor alternativas para a localização de uma arquifilologia no domínio da vida frente ao Real, ao recusar o antropocentrismo do campo literário. Explorando a teoria gravitacional do físico teórico holandês Erik Verlinde, que sugere que a gravidade seria uma qualidade emergente da informação a dividir o espaço físico emergido e um segundo espaço por vir, a inorganicidade da literatura diagnosticada na máxima batailleana seria levada a um Outro lugar. O desejo de expressar imageticamente um mundo por vir não estaria sob monopólio humano, mas sim expresso em um funcionamento cósmico desde sempre indiferente a ruína da tradição mimética.

Palavras-chave: Arquifilologia; Objeu; Gravidade; Imaginação.
\end{abstract}

\begin{abstract}
We witness, nowadays, a critical moment for the thinking process, expressed in similar manners along several study areas. Within philology, the exhaustion of the auerbachian mimetic model is experienced, as the notion of the lacanian Real takes over the western literary sensitivity. This assumption led to a morbid paradigm of existence, expressed in the works of Heidegger, Lacan and Agamben, as well as in the unbalanced contemporary readings of the bio-
\end{abstract}


political paradigm presented by Foucault, "to make live and to let die", which tend to see only the fundaments of thanatopolitics in the encounters with the Thing. The present article sees to propose alternatives for the localization of an archiphilology in the domains of life against the Real, by refusing the anthropocentrism of the literary field. Exploring the gravitational theory of the Dutch theorist physicist Erik Verlinde, which suggests that gravity would be an emergent quality derived from the information which divides the emerged physical space and a second space yet to come, the inorganicity of literature diagnosed by the battailean maxim would be taken to an Other place. The desire to express imagetically a world to come would not be within human monopoly, but express in a cosmic behavior forever indifferent to the ruins of mimetic tradition.

Keywords: Archiphilology; Objeu; Gravity; Imagination.

\section{Preâmbulo: A grande crise}

A crise é mais que moral, é mais que ética, política, psicológica, filosófica, artística, literária ou espiritual. Ao que podemos observar, o domínio de configuração de nossa crise do pensamento atinge proporçôes cósmicas. Nossa visão imediatamente expandida e irremediavelmente limitada da escala de movimentação das coisas existentes ${ }^{1}$ levou-nos a simpatizar com o vazio entre o próton e sua nuvem de elétrons, entre o sistema solar e Proxima Centauri, entre a Via Láctea e Andrômeda, entre nosso aglomerado de galáxias locais e os limites visíveis do universo: entre nossos olhos e a última camada epitelial do titã ôntico que nos é dado experienciar em imagem. Esse vazio das proporçóes espaciais, que ao se fundir com o tecido outrora imaterial do tempo acaba por se apresentar como um único grande movimento, dança ou sinfonia; essa zoológica máquina teatral que não cessa de convocar novos atores para o palco: eis o que parece colocar em cheque todo o atual funcionamento da sensibilidade humana.

A vertiginosa verdade inerente a tal colossal imagem cósmica jamais teria se tornado possível sem uma via de comunicação aberta entre um número consideravelmente assombroso de distintas formas de vida humanas e suas idiossincráticas manifestaçôes de talentos ou formulaçôes alquímicas. ${ }^{2}$ A internet nos sugere que tais formas de vida humanas conseguem se comunicar mutuamente - isto é, afetar-se mutuamente - através da confecção e compartilhamento de imagens de si. Assim, o método da tela de computador e da fibra ótica que transporta impulsos de dados binários e se decodifica na forma de imagem (por ora visual e/ou sonora) parece algo próximo à possibilitação técnica da reconquista de Babel: o milagre bíblico da glossolalia, sob o qual o desentendimento linguístico adquirido pelo pecado da arrogância estaria finalmente revogado.
1 "A ciência, ao fazer seus registros, grava e transmite a estrutura rítmica na qual os monstros da fantasia se tornam os condutores da vida que determinam o futuro" (WARBURG, Aby. "Introdução a mnemosine", 2015, p. 365).

2 Formulação alquímica pode ser pensada como uma categoria de práxis poética que nos permite integrar historicamente as ruínas do grupo de interesses que compunham o trivium e quadrivium medievais aos gestos tecnológicos da contemporaneidade, como a engenharia nano-robótica, a música inteiramente gerada por computador e os mais velozes jogos virtuais. 
3 BENJAMIN, Walter. Sobre o conceito de história, [1940] 1985, p. 226.
A diferença crucial entre o mito e a sua presente realização é a virada diabólica que profeta algum gostaria de clariver: o aspecto vampiresco adotado pelo pneuma hágion que parasita nossas línguas e corpos, que não parece conhecer limite, não parece conhecer preto nem branco e que por isso mesmo se atreve dançar em toda a escala de cinza que um corpo pode muito bem não suportar. Pneuma akatarthon: a imundice ruidosa da incessante fabricação de imagens antrópicas tornou-se indistinguível de sua divindade.

Assim, a crise é espiritual: o sensível do mundo, sua imagem, forma um caleidoscópico emaranhado estético que nos propulsiona, com as asas presas, ${ }^{3}$ na direção do movimento espaçotemporal, de cuja majestade mal conseguimos filtrar o necessário para manter as enfermidades cancerígenas alhures. De seu magnânimo colorido só podemos extrair uma verdade: sua tendência fractal de fazer borbulhar aisthesis, de realizar e fazer aparecer novas verdades a cada instante.

A crise é então literária: pois desse incessante borbulho metamórfico que tornou-se a imagem do mundo nos é emocionalmente impossível extrair um drama que consiga pontuar os episódios de nossa própria vida sublunar numa proporção adequada à dinâmica geral. $\mathrm{O}$ aspecto cômico que empacota toda tragédia é inelutável, mas mostra-se igualmente insuficiente em sua manifestação de autossuficiência trágica que é o cinismo. O ópio do século é a farsa da autoisenção da bricolagem cósmica, mas igualmente cínicos mantêm-se os baluartes das ortodoxias eclesiásticas cujo imaginário narrativo não mais consegue conter o rugido da selva.

É artística: pois o gesto artístico até então parecia ser o de um corte, de uma lira, um rasgo que estabeleceria algo de uma organização e apresentaria, sob signo estético, algo de uma origem, arkhé, dentro dos limites de seu aglomerado, dentro do cerco da montagem resultante de sua bricolagem espiritual. Entretanto, na atual desenfreada escalada de escalas que sofremos não há nada que pareça digno de exclusão. $\mathrm{O}$ excluído torna-se foracluído, toda intimidade extima, a ex-sistência toda uma in-sistência: solo satiricamente fértil para a arte, mas virtualmente arenoso para o gesto artístico, seus arquivos e suas heranças.

É filosófica: pois a constância do ser abre espaço e tempo para a inconstância da metamorfose, irrevogável, triunfante e tirânica em seus nublados - obnubilados - horizontes. A magnitude de tal movimento cósmico irrefreável acaba por avivar a brasa da vida, cuja languida fumaça chamava-se metafísica, e engole a carne de todos na escorregadia inapreensibilidade que é sua verdade. As mônadas se revelam ser pouco menos que borbulhos químicos de uma sopa no braseiro, e a nenhuma cristalização é dada sequer a menor esperança de escapar a efemeridade do tectonismo que funde e 
confunde tudo e todos, humano e não-humano. Lama, sopro e angústia escorrem por todos os poros de uma humanidade cuja consciência de morte lhe permite, acima de tudo, assistir a própria vida enredada por tal grotesco espetáculo de contaminação ôntica (hontologie, diz Lacan). Avairada em sua capacidade de imaginar as bordas daquilo que funda e finda a partitura da existência, à percepção ontológica não é mais dado ver o $D a$ que outrora poderia permitir sein.

A crise é, portanto, psicológica: pois qual o limite do inconsciente em tal babilônico jardim fluvial? Não é meu crânio, tampouco a área resultante da fusão dos crânios de meus pais, irmãos e irmãs. Não são as minhas memórias, as cores da sala de aula de minha infância ou o relevo de minha cidade natal e seus habitantes: a cultura acumulada dos continentes de minha história. Não é somente um amálgama das narrativas literárias dos clássicos ocidentais conhecidos e desconhecidos, da feitiçaria mitológica municipal e das atômicas superstiçôes locais. Não é apenas o desenho da forma humana, mamífera, cordada ou deuterostômia; nem o sopro da existência orgânica, a serena sabedoria vegetal ou a sóbria frieza da rocha. ${ }^{4}$ Em um único refrão, todos esses elementos se apresentam como cheiros, sabores e pinceladas de um colossal sonho cujo produto é a própria vida em suas inúmeras e incontáveis manifestaçôes dinâmicas. Nesse cenário, quem é esse que irrefreavelmente deseja petit a? Será aquilo que chamamos 'sujeito' o petit a do sonho cósmico?

É política: pois há outros além de mim sendo atravessados pela mesma virilidade linguística. Amparados por um maior ou menor grau de cinismo abnubilador (neste caso, $a b$ - e não $o b$-: um afastamento da bruma selvagem em direção ao espelho), há incontestáveis provas de um número assombroso de formas de vida humanas antenadas à mesma promiscuidade divina que se tornou tekhné, geniosa entidade tradutora das mais desvairadas imagens imateriais para o meio físico, e suas consequências à insanidade de Morfeu.

É ética: pois os entes parasitados pelo transborde linguístico vivem corpos, vivenciam corpus, e podem vir a ter seu influxo significante temporária ou definitivamente calado, rompido, graças à enfermidade ou trauma da carne. Da necessidade de manter Simbólico e Real em registros diferentes tomamos isto: a técnica, a retórica ou mesmo a arte conseguem barganhar até um dado limiar, a partir do qual, por algum motivo que seja, tanto a célula cancerígena quanto o torturador político parecem ambos surdos às preces e químicos, declarando o triunfo sobre o corpo. Da mesma forma afeta-se a crise de relaçóes entre corpos e corpus: o peso milenar do ilimite linguístico choca-se com a leveza efêmera e contingente da vida.

É, obviamente, moral: pois quando a alma experiencia verdadeiramente
4 Precisamos, aqui, da imediata lucidez de Nancy: "Así, lo que Freud había nombrado con torpeza lo 'inconsciente', como heredero que era de una tradición romántica, no es para nada otra consciencia, o una consciencia negativa: es sencillamente el mundo" (NANCY, Jean-Luc. El sentido del mundo, 1993, p. 77-8) 
5 JOYCE, James. Finnegans wake, 1976, p. 628.

6 Voz da morte, diria Agamben (AGAMBEN, Giorgio. A linguagem e a morte, 2006, p. 67-8).

7 DEGRASSE TYSON, Neil; GOLDSMITH, Donald. Origens: catorze bilhóes de anos de evolução cósmica, 2016, p. 36-7.

8 Nota de rodapé in: WARBURG, Aby. Histórias de fantasma para gente grande, 2010, p. 303. o esfacelamento das narrativas, não há prescrição outra que não a ingestão de tudo que o corpo consiga suportar.

Então a crise é, finalmente, cósmica.

\section{O (i)limite cósmico}

Ao observar as ínfimas partículas estruturantes dos hádrons, cadeias cujos exemplos mais estáveis são prótons e nêutrons, o físico estadunidense Murray Gell-Mann havia chego ao som do nome que gostaria de presentear às recentes descobertas antes mesmo de conhecer sua grafia adequada. Kwork haveria surgido como uma possibilidade inicial, mas foi a passagem de Finnegan's Wake que determinaria sua escrita definitiva:

$$
\begin{aligned}
& \text { - Three quarks for Muster Mark! } \\
& \text { Sure he hasn't got much of a bark } \\
& \text { And sure any he has it's all beside the mark. }
\end{aligned}
$$

(Livro 3, Capítulo 4)

Quark aparece no extrato de Joyce não apenas como uma onomatopeia para o crocitar das gaivotas mas, primordialmente, como coisa que vem em três. Essa qualidade se apresentou perfeitamente adequada a Gell-Mann, dado que as partículas em questão se agrupam em trios; e assim o compartilhamento do significante foi perpetrado. Quark, a partícula atualmente tida como fundamental à formação de toda matéria, adentra o conhecimento humano em 1964 como significante aberto, pura sonoridade animalesca, ${ }^{6}$ antes de tornar-se letra emprestada do romance que veio a implodir a língua inglesa. $^{7}$

Talvez essa seja uma elucidativa introdução ao desenho do momento histórico em que vive nossa sensibilidade literária.

Tudo aquilo que hoje desengonçadamente tentamos agrupar sob o título de literatura nasce graças à condiçáo porosa do ser do homem no mundo. A loi de participation, que Aby Warburg empresta de Levy-Brühl em seu escrito sobre Sphaera Barbarica, i.e. "a observação de uma consciência fluida dos limites entre o Eu e o mundo ao redor", ${ }^{8}$ diz da predisposiçáo do pensamento para oscilar através de fronteiras nunca solidamente demarcadas entre a menor das partículas e a mais distante estrela dos confins cósmicos. Destes mistérios brutos, envoltos em gelada incandescência, uma face específica se anuncia e encontra receptáculo no fundo vítreo de nossa percepção: trata-se de sua imagem, sua parcela de participação no sensível, essa forma de ser mais empática do que a matéria real mas ainda assim estrangeira, antecipadamente alheia ao pensamento. 
São as imagens - dos átomos, das estrelas, das rochas e de tudo que vive - que nos incitam à inelutável dança da organização, da ordenação e da fabricação de origens (todas performances referentes ao termo grego arkhé), por razões tão numerosas que qualquer lista historiográfica pareceria fastidiosa. Urgência da consciência de morte (ser-aî), canto das infindáveis maravilhas da vida (sereia) ou gozo mecânico de asserção da existência de si (sinthoma), a literatura existe e persiste, cada vez mais percebida como parcela indissociável da pura linguagem que parasita todo o humano.

A abóboda celeste desde sempre foi tomada como o plano literário dos deuses, entidades maiores que resistem ao tempo ceifador de todas as criaturas sublunares. Uma minuciosa cartografia estelar auxiliou distintas culturas na apreensão de padróes de comportamento da physis, permitindo que as comunidades humanas pudessem, por exemplo, antecipar a chegada do inverno e calcular previamente quantidades adequadas de estoque de alimento. ${ }^{9}$ Os deuses utilizariam a abóboda celestial para escrever sua complexa existência, cabendo aos seres menores a elaboração das cifras e recortes do enigma ali introduzido. Entretanto, jamais encontramos casos nos quais as elaboraçóes teriam sido úteis em sua completude. Por todos os lados é seguro encontrar uma significante parcela de inutilidade prática: para o posicionamento cósmico do raio fora necessário ora uma intrincada série narrativa de casos românticos envolvendo o patrono da entidade; ora serpentes, tinturas corporais e perigosas danças em grupo: detalhes estéticos que dizem menos da musa e sua imagem que do músico e sua imaginação. Podemos sugerir esse como o registro que acolhe a literatura.

Essa localização é determinante: é radicalmente diferente encarar a literatura como mais uma ferramenta, mais um capítulo na derradeira odisseia de domesticação tecnológica da physis para a qual o ser humano constantemente se aprimora, seja apoiando-se sobre a mitologia semita, a vulgata darwinista, a fábula capitalista ou em aspectos de todas simultaneamente. ${ }^{10}$ Ao dizer que a literatura é, inversamente, um excesso, uma vibrante, instigante, inútil tintura que jorra da tentativa de ordenação cósmica, ${ }^{11}$ uma distinta corrente teórica procuraria salvá-la de sua participação na escravocracia cínica para conservá-la próxima ao pensamento em sua condição primordial frente ao sensível, que é a de um curioso ser bricolante. ${ }^{12}$

Hoje, os deuses são poeira e luz, e escrevem somente danças. Se antes um meteoro poderia cortar o bidimensional manto celeste para incitar a elaboração de uma mensagem, atualmente nosso olhar mecanizado sobre ele ultrapassa a abóboda estratosférica e coloca de imediato a questáo do cálculo de seu giro ao redor de um segundo agrupamento de quarks mais denso. Este agrupamento, por sua vez, exige a previsão de seu próprio movimento ao redor de um terceiro, necessariamente maior, levando sucessivamente ao
9 Ou qualquer outra fábula sobre o aspecto sobrevivente de nossa existência que queiramos formular.

10 "Entre o lojista, o depravado rico e o devoto acocorado à espera da salvação, houve também muitas afinidades, inclusive a possibilidade de estarem unidos numa só pessoa”. (BATAILLE, Georges. A experiência interior, 2016, p. 42).

11 Ordenação cósmica a ser entendida, aqui, como sismografia. Escreve Warburg, em suas Memórias da viagem à região dos indios pueblos na América do Norte: "[...] [A]gora, em março de 1923, aqui em Kreuzlingen, numa instituição fechada, onde me sinto como um sismógrafo feito de peças de madeira vinda de uma planta trazida do Oriente, transplantada nas férteis planícies baixas do norte alemão e inoculada com um ramo italiano -, dou enfim vazão aos sinais que vou recebendo, pois nesta época de declínio caótico até o mais fraco tem a obrigação de reforçar a vontade pela ordenação cósmica" (In: WARBURG, Aby. Histórias de fantasma para gente grande, 2015, p. 261-2).

12 Afinal, é o próprio Darwin quem escreve: "Variations neither useful nor injurious would not be affected by natural selection, and would be left a fluctuating element, as perhaps we see in the species called polymorphic" (DARWIN, Charles. The origin of species, [1859] 2004, p. 94). A literatura não é senão isso: species, talvez mais no sentido aristotélico que taxonômico (ou seja, mais próximo de phantasma), de natureza polimórfica. 
13 DEGRASSE TYSON, Neil; GOLDSMITH, Donald. Origens, 2016, p. 66.

14 "El lenguaje es el objeu de la filologia. [...] La filologia, que como todo lenguaje es lenguaje y por eso el juego de su movimiento no es programable, es lenguaje en el trajeu". (HAMACHER, Werner. 95 tesis sobre la filologia, 2011, p. 21). desenho das órbitas de cometas, planetas, estrelas, galáxias e aglomerados de galáxias. Por muito tempo, as fórmulas físicas elaboradas por Isaac Newton no século XVII provaram-se perfeitamente suficientes para o trânsito do alcance técnico humano em uma determinada escala: a sonda Juno, enviada a Júpiter no dia 4 de julho de 2016, possui suas coordenadas de viagem calculadas através da exata mesma equação, a mesma obra linguística, gravada nos Principia Mathematica de 1687. Contudo, a interação entre a matéria e sua imagem e o pensamento e sua imaginaçáo seguiu desdobrando e desenvolvendo os limites das proporçóes do cosmos, e tanto para fora quanto para dentro as fronteiras cósmicas ainda resistem à assimilação simbólica apresentada pelo teorema das órbitas newtoniano:

Quando examinamos o aglomerado de Coma [Berenices] [...] descobrimos que todas as suas galáxias membros se movem mais rapidamente do que a velocidade de escape para o aglomerado, mas apenas se estabelecemos essa velocidade a partir da soma de todas as massas da galáxia consideradas uma a uma, o que estimamos a partir dos brilhos das galáxias. Portanto, o aglomerado deveria se dispersar velozmente, mal e mal deixando um vestígio de sua existência de colmeia, depois que apenas algumas centas de milhões de anos, talvez um bilhão, tivessem se passado. Mas o aglomerado tem mais de 10 bilhóes de anos, é quase tão velho quanto o próprio universo. $\mathrm{E}$ asim nasceu o que continua a ser o mistério mais duradouro da astronomia. [...] Talvez a "massa ausente" necessária para unir as galáxias do aglomerado de Coma realmente exista, mas de alguma forma invisível, desconhecida. Por algum tempo, os astrônomos deram ao problema da massa ausente o nome de o "problema da luz ausente", pois a massa tinha sido fortemente inferida a partir do excesso de gravidade. Hoje, com melhores determinaçóes das massas dos aglomerados de galáxias, os astrônomos usam o apelido "matéria escura", embora "gravidade escura" fosse mais preciso. $^{13}$

Por que a questão da matéria, gravidade e energia escura, hoje a problemática mais envolvente da astrofísica, poderia interessar a filologia? Se seguirmos na linha de pensamento sugerida inicialmente, de que são as imagens do mundo que incitam algo de um jogo linguístico, ${ }^{14}$ literatura, precisamos então abarcá-las na radicalidade de seus limites, como mineradores tateando a última camada rochosa de um escuro fosso. Em outras palavras, é o caso de observar como as ciências ditas "naturais" (aquelas que travam com maior seriedade uma luta contra o antropocentrismo algo obscurantista das outras, ditas propriamente "humanas") tratam o Real, o terreno que resiste a simbolização, resiste à formulação linguística que deu conta de calcular o movimento de queda de maçãs e órbitas de planetas próximos. No caso da problemática de cálculos de movimentação dos corpos celestes 
de massa colossal (estamos falando de aglomerados de galáxias), as propostas atuais podem conter interessantes consequências metafóricas.

Erik Verlinde, físico teórico holandês, vêm ganhando notoriedade por suas teorias acerca de uma qualidade emergente ${ }^{15}$ da gravidade a partir de estudos em escala quântica (na qual a física newtoniana também parece não surtir efeito), que poderia explicar, através de cálculos e elucidações um tanto alternativas em relação ao caminho trilhado por Newton com a adição das considerações de Einstein, a questão de uma massa impossível de se observar. Numa linha teórica desenvolvida ao longo de seus dois artigos, On the origin of gravity and the Laws of Newton, de 2010, e Emergent gravity and the Dark Universe, de 2016, ${ }^{16}$ Verlinde sugere que "the central notion needed to derive gravity is information. More precisely, it is the amount of information associated with matter and its location, [...] measured in terms of entropy." ${ }^{17}$ Diferentemente da ideia de que um aglomerado de massa é primordialmente responsável pela distorção do tecido espaçotemporal ao seu redor, e que tal deformação produziria os efeitos gravitacionais observáveis (ou seja, que gravidade deriva da matéria), como desenha Einstein, Verlinde nos diz que é a informação, de qualidade virtual, imaterial, associada a matéria e sua localização, que faz a gravidade emergir, dentro de um quadro cujos termos essenciais para sua compreensão são termodinâmicos (entropia).

"Space", lembra-nos Verlinde em uma época onde espaço e tempo já não mais podem ser compreendidos de maneira radical e verdadeira quando separados, "is in the first place a device [um dispositivo] introduced to describe the positions and movements of particles. Space is therefore literally just a storage space for information." ${ }^{18}$ Para a compreensão de sua teoria de gravidade, é primeiro importante lembrar a qualidade virtual do próprio dispositivo de compreensão, que é o espaço. Levando em conta este dado, ou seja, o da arbitrariedade inicial para o desenho de um modelo espacial, "[o]ne could assume that information is stored in points of a discretized space (like in a lattice model). But if all the associated information would be without duplication, one would not obtain a holographic description. In fact, one would not recover gravity." ${ }^{19}$ A duplicação de natureza holográfica, virtual, da matéria é chave para a teoria gravitacional de Verlinde, e aqui chegamos a parte que nos interessa:

Thus, we are going to assume that information is stored on surfaces, or screens. Screens separate points, and in this way are the natural place to store information about particles that move from one side to the other. [...] [T] he screens that store the information are like stretched horizons. On one side there is space, on the other side nothing yet. [...] The screen bounds the
15 "Essa arqueologia a que chamamos ruinologia é uma prática desinteressada pela origem; porém, sequiosa da emergência de um determinado fenômeno, para cuja correta avaliação deve tornar a se confrontar com as fontes e a tradição" (ANTELO, Raul. $A$ Ruinologia, 2016, p. 15, grifos meus).

16 Uma primeira versão de ambos foi publicada pela Cornell University Library e se encontram disponíveis, respectivamente, em: https://arxiv.org/ abs/1001.0785 (2010); https:// arxiv.org/abs/1611.02269 (2016).

17 VERLINDE, Erik. "On the origin of gravity and the laws of Newton", p. 2.

18 Ibidem, p. 6.

19 Ibidem, p. 6. 
20 Ibidem, p. 6-7 (grifos meus)

21 ANTELO, Raul. A ruinologia, 2016, p. 25-6. emerged part of space, which contains the particle, and stores data that describe the part of space that has not yet emerged, as well as some part of the emerged space. ${ }^{20}$

Essas telas de dimensão quântica devem ser entendidas como horizontes de eventos, a última curva material antes do espaço negativado de um buraco negro, bidimensionalizados de maneira a dividir planos: de um lado, o espaço físico, já emergido, atual, material; de outro, nada ainda, potência, um vir-a-ser. A tela separa estes planos e estoca informação (virtual) que descreve a parte do espaço ainda por emergir, contendo também descriçôes (inscriçóes) de partes do espaço emergido, material. É essa informação, sobre o deslocamento da massa dentro do plano material, combinado com uma descrição ou uma intuição da potência, do nada-ainda, o que resultaria em uma força gravitacional emergente.

Somos inevitavelmente tragados pela urgência das metáforas.

\section{Virtualidade e materialidade: a vida das imagens}

Sobre a imagem, Raul Antelo escreve, em sua Ruinologia:

Sabemos que os gregos reservavam para o conceito de imagem dois termos, o de eidolon e o de eikon. Eidolon era a imagem de um sonho, a aparição de um deus ou um fantasma ancestral. Não interessa, no eidolon, o que a imagem faz, aquilo de que ela é capaz, mas aquilo que ela é; porém, quando a língua grega cunha o termo eikon, mais ou menos na mesma época em que começa a circular o conceito de mimesis, o novo significante, eikon, logo desvalorizou eidolon, que a partir de entâo adotou uma significação meramente negativa, como a cópia ou imitação inerte, enquanto eikon passou a exigir definiçôes ontológicas relevantes, tais como a distinção filosófica entre aparência e essência, que se tornava assim necessária para as imagens existirem. Já no caso da latina imago, a imagem por ausência ou esvaziamento, o corpo e o meio estáo uniformemente implicados nela, na medida em que é no lugar do corpo ausente do morto que se instalam as imagens. Mas elas permaneceriam como simples recurso artificial, ao virem ocupar o lugar vago do defunto, ora chamado imago, ora de caput mortuum (Michel Leiris) ou mesmo objeto a (Lacan). O corpo perdido é efetivamente substituído pelo corpo virtual da imagem e, nesse ponto, atingimos, enfim, o paradoxo etimológico da imagem: a imagem torna visível uma ausência ao transformá-la em uma nova forma de presença. Portanto, toda imagem repousa numa analogia com o corpo físico e no fato de os corpos também funcionarem como meios, a tal ponto que as imagens simplesmente acontecem entre nós. Elas são, a rigor, o único acontecimento. ${ }^{21}$ 
Mais do que adentrar, neste momento, o complexo debate da distinção entre eidolon e eikon ${ }^{22}$ interessa-nos pinçar os três elementos da operação imagética destacados por Antelo em sua tradição latina - corpo, meio e a própria imagem - e o jogo de relaçôes estabelecidos entre material e imaterial, físico e virtual. Insistir no fato de que uma imagem "acontece entre nós”, e que os corpos também funcionam como meios capazes de acolher a imagem, salva-nos de uma tradição fenomenológica cuja derradeira consequência é o estabelecimento de uma primazia da percepção, marca de um antropocentrismo que gostaria de ver no homem a verdadeira gênese das imagens. Entretanto, como nos aponta Emanuele Coccia em A vida sensivel,

A experiência do espelho coincide com a assimilação de uma dimensão de irredutibilidade da imagem em relação ao lugar da percepção. A imagem, o sensível, existe em um lugar diferente daquele onde a assimilamos. Ela existe no espelho antes de chegar ao órgão da percepção (nesse sentido, a imagem é simultaneamente objeto e sujeito). Há quase uma primazia da imagem sobre a imaginação, uma primazia do sensível sobre a sensação, que não é apenas de ordem cronológica. A afirmação de que o sensível existe, no sentido forte do termo, de que o sensível é um gênero de ser, uma forma de existência, leva a concluir que é preciso observar a gênese da percepção do ponto de vista da imagem mesma e não a partir do sujeito que a percebe. O verdadeiro centro da percepção é a imagem. Observada a partir desse ponto de vista, toda forma de conhecimento sensível é uma aceitação passiva de uma imagem perceptiva que já se produziu fora de nós. Não há uma ação específica do sujeito no ato da percepção: perceber não significa produzir a imagem de algo, mas recebê-la. Do ponto de vista do sensível quanto tal - do ponto de vista da imagem -, o espelho ou o fundo do olho são exatamente a mesma coisa. Não passam de superfícies capazes de acolher a imagem, de não lhe opor resistência. A questão não é simplesmente topológica: as imagens se geram fora dos órgãos de sentido e, sobretudo, sem o aporte deles. Do ponto de vista estritamente ontológico, o sujeito não é nem o lugar de nascimento da imagem, enquanto ser do sensível, nem a sua causa. O sensível é sensível antes de ser percebido e indiferentemente do fato de ser atualmente percebido. ${ }^{23}$

Do ponto de vista da imagem, espelho, olho, corpo ou tela não são outra coisa que não meio: espaço material capaz de acolher uma imagem imaterial, sem corrompê-la ou corromper-se a si mesmo no processo de recepção, configurando assim uma "paixão não transformadora". ${ }^{24}$ Ainda assim, para ser percebido enquanto tal, enquanto receptor de imagem, o meio precisa ele próprio fazer jus à potência que qualifica o tipo de vida recebida, esse tornar "visível uma ausência ao transformá-la em uma nova forma de presença" ao ocupar, como fantasma, o lugar do defunto, o lugar de uma coisa análoga a vida de maneira simétrica a qual imagem é análoga ao corpo
22 Por ora basta-nos a nota do fracasso da disciplina almejada por Heidegger, a "idolologia”, frente à emergência das Kulturwissenschaften (ALLOA, Emmanuel. "Da idolologia. Heidegger e a arqueologia de uma ciência esquecida”. Em: (org.) Pensar a imagem, 2015, p. 93-113).

23 COCCIA, Emanuele. A vida sensivel, 2013, p. 34-5.

24 Ibidem, p. 31. 
25 Ibidem, p. 35.

26 LACAN, Jacques. "A instância da letra no inconsciente", 1998, p. 521 .

27 Aqueles mesmos que escrevem "o que ouve, nunca o que houve" (Oswald de Andrade, citado por ANTELO, Raul. A ruinologia, 2016, p. 17). físico: ou seja, no nível de potência. Tudo repousa nessa analogia, não de maneira mimética, mas antes estética: uma multiplicação da existência sensível que distorce o cogito, dado que a experiência frente ao espelho permite nos observar "ao mesmo tempo aqui e lá: em mim como corpo e alma, sobre o espelho como imagem sensível." 25 Algo não tão distante da célebre virada do cogito perpetrada por Lacan em "A instância da letra no inconsciente": "penso onde não sou, logo sou onde não penso"26 (in: Escritos, 1998, 521).

No caso, poderíamos imaginar um esquema similar a este:

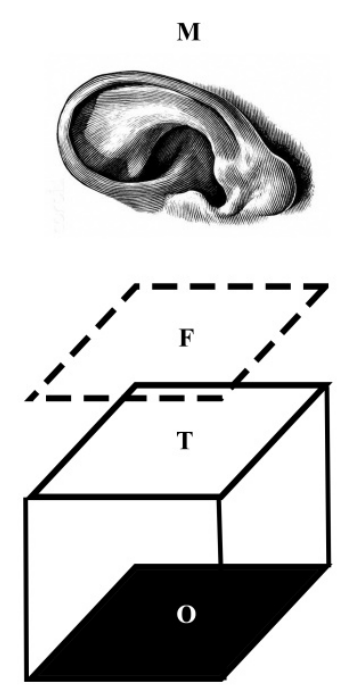

Figura 1: Tela, Fantasma, Matéria

Entendemos M como matéria, espaço já emergido, plano físico onde vivem os corpos; ${ }^{27} \mathrm{~T}$ como a tela, o meio acolhedor de imagem, pensada dentro dos termos apresentados por Erik Verlinde, ou seja, como umbral que destaca de um lado o meio físico emergido e de outro o nada-ainda em potencial, por emergir; $\mathrm{O}$ como esse outro lugar, o locus de potência que caracteriza a tela enquanto tal (i.e. enquanto meio, acolhedora de imagem), Real, das Ding, Grand ou petit a; e por fim F, fantasma ou imagem, que acontece no entre-lugar, com aporte material mas entendido aqui como de natureza imaterial. Devemos entender esse destaque entre F e T como que em nível quântico, pensar o entre-lugar da imagem como um intermédio microscópico entre tela e pneuma, por um lado, e tela e $\mathrm{O}$, por outro.

Nem mesmo Hobbes, no caminho de escrita de um monumento de positivação da qualidade lupina do papel do estado, poderá se eximir de ter de lidar com um esquema semelhante. Percorrendo uma via de escalas algo similar àquela da introdução deste presente artigo, Hobbes encontra a necessidade, nos dois primeiros capítulos do Leviatã, de inscrever uma breve crítica espiritual: 
Tudo o que em nós é pressionado são apenas movimentos diversos (pois movimento produz nada mais que movimento). Mas sua aparência, a nós, acordados ou sonhando, é uma Imaginação [gr. fantasía, lat. phantasma]. Assim, da mesma forma que, ao pressionarmos, esfregarmos ou golpearmos os Olhos, imaginamos uma luz e, ao pressionarmos a Orelha, imaginamos um ruído, os corpos que vemos ou ouvimos fazer e produzem o mesmo efeito por sua ação vigorosa, embora invisível. Pois, se aquelas Cores e aqueles Sons estivessem nos Corpos ou nos Objetos que os causam, não poderiam ser separados deles, mas o são por meio da reflexão, conforme podemos ver nos espelhos e nos Ecos: pelos quais sabemos que a coisa que vemos está em um lugar; a aparência, em outro. E, embora a certa distância, o próprio objeto real pareça investido da imaginação que ele causa em nós; ainda assim, o objeto é uma coisa e a imagem ou a imaginação é outra. De modo que os Sentidos, em todos os casos, não são nada mais que a Imaginação original causada [...] pela pressão, isto é, pelo movimento das coisas externas sobre nossos Olhos, Orelhas e outros órgãos determinados para isso. ${ }^{28}$
28 HOBBES, Thomas. Leviatã, ou matéria, forma e poder de um estado eclesiástico e civil, [1651] 2015, p. 18.

29 Ibidem, p. 18, grifos do autor.

30 BATAILLE, Georges. A literatura e o mal, 2015, p. 22.

A elaboração de Hobbes parece coincidir, em parte, com aquela de Coccia e Antelo no que diz respeito a asserção da vida da imagem para além da matéria que a abriga, "conforme podemos ver nos espelhos e nos Ecos". Entretanto, em sua construção crítica há uma diferença crucial, expressa no parágrafo anterior à citação: "Todas essas qualidades chamadas de Sensiveis são - no objeto que as causam - apenas um grande número de movimentos da matéria que pressiona nossos órgãos de formas diversas." ${ }^{29}$ É em termos materiais-orgânicos que Hobbes pensa a imagem, ainda que se ocupando mais da pressão por ela exercida no meio do que de sua qualidade física, propriamente. Entretanto, isso vai em desencontro a noção de "paixão não-transformadora" sustentada por Coccia em sua leitura de Averróis. Da mesma maneira, há uma desavença para com a teoria de Verlinde sobre a importância da qualidade virtual da informação, que doravante podemos entender simplesmente como imagem.

Essa oposição a uma leitura hobbesiana da materialidade do fantasma é também expressa por Bataille ao frisar a inorganicidade da literatura e sua possibilidade de desnudar o fundo sem estabelecer novo fundamento:

Só a literatura podia desnudar o jogo da transgressão da lei sem a qual a lei não teria fim - independentemente de uma ordem a criar. A literatura não pode assumir a tarefa de organizar a necessidade coletiva. Não cabe a ela concluir: "aquilo que eu disse nos obriga ao respeito fundamental pelas leis da cidade"; ou, como faz o cristianismo: "aquilo que eu disse (a tragédia do Evangelho) nos coloca na via do Bem” (ou seja, na prática, da razão). A literatura é mesmo, como a transgressão da lei moral, um perigo. Sendo inorgânica, ela é irresponsável. Nada repousa sobre ela. Ela pode dizer tudo. ${ }^{30}$ 
31 Escreve Rancière: "Do que se está falando e o que precisamente nos é dito quando se afirma que daqui em adiante não há mais realidade, apenas imagens? $\mathrm{Ou}$, ao inverso, que doravante não há mais imagens, somente uma realidade representando sem cessar a si mesma? Os dois discursos parecem opostos. Todavia, sabemos que não param de se transformar um no outro em nome de um raciocínio elementar: se só há imagens, não existe mais um outro da imagem. E se não existe mais um outro da imagem, a noção mesma de imagem perde seu conteúdo, não há mais imagem" (RANCIÈRE, Jacques. $O$ destino das imagens, 2012, p. 9-10).

32 No sentido agambeniano, ao falar da Voz: "Mas, dado que esta Voz [...] tem o estatuto de um não-mais (voz) e de um náo-ainda (significado), ela constitui necessariamente uma dimensão negativa. Ela é fundamento, mas no sentido de que ela é aquilo que vai ao fundo e desaparece, para que assim o ser e a linguagem tenham lugar" (AGAMBEN, Giorgio. A linguagem e a morte, 2006, p. 56).

33 Escreve Christian Dunker: "O que define uma forma de vida é a negatividade, a falta, o corte ou o vazio que a faz se apresentar ao modo de uma elipse sem centro, personalidade sem qualidades, herói em exílio, indivíduo isolado ou sobrevivente. Trata-se do que Calligaris chamou de paradigma mórbido da modernidade, do qual a psicanálise partilha e que caracteriza a subjetividade moderna como inventário de desencontros, falsas restituições, promessas irrealizadas e elaboraçốes melancólicas. Se há uma estrutura fundamental da modernidade, é a melancolia. Mas o sujeito moderno é antes de tudo um melancólico de uma melancolia atípica, pois se caracteriza por não aceitar seu próprio destino. Nossos heróis são, ao mesmo tempo, senhores de suas histórias de vida, apresentadas como obras de autodeterminação, mas também escravos do luto por uma experiência que não conseguem lembrar, reconhecer ou incorporar. Eles evocam existências póstumas, desprovidas de acontecimentos, como é o caso de nosso Brás Cubas, ou vivências amnésicas, como nosso Macunaíma, ou ainda
Ou seja, nossa leitura da problemática da imagem, conforme desenhada na Figura 1, leva-nos a seguinte conclusão: uma tela só é percebida enquanto tal, enquanto meio, enquanto acolhedora de uma imagem, quando o que subjaz e fundamenta o conjunto de sua operação é um espaço por vir. Aquilo que distingue a tela de qualquer outra superfície despida de imagem (ainda que isso seja impossível de se imaginar) é o vórtice de potência emergente que qualifica a imagem em seu quesito fantasmal, análoga a vida e ao corpo material mas ainda assim outra ("outra coisa"). ${ }^{31}$ Isso quer dizer que o corpo, ao ouvir o fantasma, o faz necessariamente de maneira obnubilada, de audição turva pelo rugido da selva inconsequente e irresponsável que necessariamente qualifica a tela do lado de lá.

Este fundamento, ${ }^{32}$ ao ser transportado para o corpo, não está longe do limite psíquico contido no paradigma mórbido da modernidade. ${ }^{33} \mathrm{O}$ lado de lá da tela arrancada é o que encara o muçulmano em Auschwitz ${ }^{34}$ : "O prisioneiro vê a Gorgona quando toca o fundo sem fundo, o fundo fofo, ao alcançar a visão do que é impossível de ver, a ausência de fundamento da autoridade, o não-humano do homem." 35 O fundamento Real é a ausência de fundamento, o imaterial que inaugura o material, noção que vem a sustentar, consequentemente, a tese 51 de Hamacher: "No hay ningún metalenguaje que no pudiera ser desaprobado por otro. Esta desaprobación es una de las historias de la filologia," ${ }^{36}$ muito provavelmente a história da modernidade.

A capacidade de vislumbre de uma esmagadora potência superiora, mãe de toda contingência e prenha de toda metaforma da matéria, contida na fórmula da sublimação lacaniana, ${ }^{37}$ seria então o ingrediente antrópico faltante para a possibilidade de uma mirabolância tal como um "universo andorinizado" sugerido em "Função e campo da fala e da linguagem":

\footnotetext{
Pois, mesmo que aparecesse entre as andorinhas algum caíde da colônia que, sorvendo o peixe simbólico do bico hiante das outras andorinhas, inaugurasse a exploraçáo da andorinha pela andorinha, cuja fantasia um dia nos comprazemos em tecer, isso não bastaria para reproduzir entre elas a fabulosa história, imagem da nossa, cuja epopeia alada nos manteve cativos na ilha dos pinguins, e faltaria alguma coisa pra criar um universo 'andorinizado'. ${ }^{38}$
}

Aquilo que faltaria, segundo Lacan, é a própria coisa faltante, a própria falta que nos mantêm cativos na ilha dos pinguins, a ausência de fundamento que sustenta toda (falta de) autoridade. Neste sentido, Lacan se faz herdeiro de Heidegger, ao sugerir que o diferencial humano seria sua capacidade de vislumbrar a clareira (ou o vazio) do ser. ${ }^{39}$ 
Entretanto, desenhado desta maneira, este já se consolidou um lugar-comum para o pensamento ocidental, ao ponto de ser tomado como paradigma. Meu objetivo, aqui, é tentar promover assunçóes diferentes sobre esse fundamento ao nos distanciar do antropocentrismo e nos aproximar, com isso, da necessidade de enxergar nesta esquematização outra coisa que não primordialmente o berço da tanatopolítica, naquela insistente leitura desbalanceada do "fazer viver e deixar morrer" foucaultiano ${ }^{40}$ que hoje popula boa parte da produção acadêmica sobre arte e modernidade.

\section{Da filologia cósmica}

Ainda que tal crítica possa parecer, em um primeiro momento, estranha, a exaustão presenciada na produção intelectual acerca da filologia é em boa parte tributária de um antropocentrismo que negou aceitar Galileo Galilei e insiste em ver no humano a medida de todas as coisas. A crítica poderia parecer fora de lugar por termos a literatura, objeto de estudo da filologia, como prática necessariamente humana, contida num último alicerce antrópico que se mantém após a enchente denominada "estudos culturais" derrubar todos os estandartes ocidentais e destronar Homero do lugar de fundador de uma disciplina notoriamente europeia. Entretanto, as noçôes de objeu e trajeu, apresentadas por Werner Hamacher em suas Tesis sobre la filología $(2011,21)$, a noção de genealogia nietzsche-foucaultiana e a importância da emergência na ruinologia apresentada por Antelo nos levam a tal escala de imagens rizomáticas, pintadas em extensas constelaçôes dinâmicas, que uma limitação para o pensamento estabelecido pelo limiar da antropogênese parece irrisório, para não dizer castrador (daí que seu limite e seu fundamento sejam ambos um só: tanatopolítica).

A filologia parece partilhar de um mal observado por Coccia quanto a filosofia:

Salvo raras exceçôes, há séculos a filosofia parou de contemplar a natureza: o direito de ocupar-se e de falar do mundo das coisas e dos viventes náo humanos cabe exclusivamente a outras disciplinas. Plantas e animais, fenômenos atmosféricos e extraordinários, os elementos e as suas combinaçôes, as constelaçôes, os planetas e as estrelas foram definitivamente expulsos do catálogo imaginário dos seus objetos de estudo. [...] Mas a negação de qualquer dignidade filosófica para natureza e cosmo teve consequências catastróficas, sobretudo no estatuto da disciplina. O primeiro foi o estranho bovarismo: a partir de então a filosofia pretendeu - a qualquer custo - ser incluída nas ciências humanas. Alternando falsos pressupostos e superficiais aspiraçôes, os filósofos sem mundo tentaram assim reformular desesperadamente o mantra do mais epigonal dos protagorismos. uma sobrevivência instrumental, como nosso Sargento de Milícias" (DUNKER, Christian. Mal-estar, sofrimento e sintoma, 2015, p. 281-2).

34 Todo o problema do campo de concentração como constructo de realidade aos olhos do muçulmano inicia-se quando, teoricamente, a lacuna entre objeto e Coisa é abolida: "[n]o universo dos campos de concentração considerado em seu aspecto mais horripilante [...] não é mais possível sustentar essa lacuna entre a realidade em sua inércia material e o domínio etéreo da Vida infinita - essa mesma lacuna é suspensa, ou seja, a própria realidade tende a coincidir com a Coisa monstruosa" (ŽIŽEK, Slavoj. Alguém disse totalitarismo? Cinco intervençôes no (mau) uso de uma noção, 2013, p. 64). Em outras palavras, o que encontra-se abolido é o resto, para pensarmos com Agamben. É como Jeanne Marie Gagnebin explora o conceito em seu capítulo de apresentação de $O$ que resta de Auschwitz: "O que resta de Auschwitz não significa, entáo, aquilo que ainda poderia sobrar, permanecer desse terrível acontecimento, algo como um famigerado 'dever de memória', uma expressão cujos usos e abusos são conhecidos. $\mathrm{O}$ resto indica muito mais um hiato, uma lacuna, mas uma lacuna essencial que funda a língua do testemunho em oposição às classificaçôes exaustivas do arquivo". (GAGNEBIN, Jeanne Marie. "Apresentação", 2008, p. 11). Ou seja, o que concerne o livro de Agamben é precisamente a lacuna, mesmo que muito estreitada, entre a experiência do campo de concentração sublimado e a Coisa. A oposição entre o muçulmano e alguém como Primo Levi, por exemplo, seria o fato de o primeiro estar dentre "aqueles que entraram no domínio proibido da áte, do horror indizível: eles encontraram a Coisa em si, cara a cara" (ŽIŽEK, Slavoj. Alguém disse totalitarismo? Cinco intervenções no (mau) uso de uma noção, 2013, p. 61), enquanto o segundo haveria sucedido em manter algo da lacuna estética psiquicamente essencial, empaticamente distanciadora, necessária para montar todo o arcabouço mnêmico que funda o testemunho. Entretanto, a finalização do livro de Agamben, com os relatos de "muçulmanos 
reformados", que retornaram da áte e puderam vir a partilhar as ruínas de memórias da época, coloca em questão esse que poderíamos chamar de um aspecto radicalmente infernal do campo de concentração ao apostar na manutenção de um outro - ainda que desmesuradamente aterrador - tipo de lacuna.

35 ANTELO, Raul. A ruinologia, 2016, p. 36-7.

36 HAMACHER, Werner. 95 tesis sobre la filologia, 2011, p. 22.

37 "E a fórmula mais geral que lhes dou da sublimação é esta ela eleva um objeto - e aqui não fugirei às ressonâncias de trocadilho que pode haver no emprego do termo que vou introduzir - à dignidade da Coisa”. (LACAN, Jacques. O seminário, livro 7 : A ética da psicanálise, 2008, p.

137). Pouco adiante, Lacan traz ao problema da sublimação um exemplo que estabelece paralelos a qualidade específica da tela que aqui tentamos trabalhar, ao falar da esdrúxula coleção de caixas de fósforo presenciada na casa de um amigo: "[E]sse arranjo manifestava que uma caixa de fósforos não é simplesmente algo com uma certa utilidade, que não é nem mesmo um tipo, no sentido platoniano, a caixa de fósforos abstrata, que a caixa de fósforos sozinha é uma coisa, com sua coerência de ser. O caráter completamente gratuito, proliferante e supérfluo, quase absurdo, dessa coleçáo visava, com efeito, sua coisidade de caixa de fósforos. O colecionador encontrava assim sua razão nesse modo de apreensão que incidia menos na caixa de fósforos do que nessa Coisa que subsiste na caixa de fósforos". (Ibidem, p. 140).

38 LACAN, Jacques. "Função e campo da fala e da linguagem", [1953] 1998, p. 277.

39 Viveiros de Castro escreve: "O homem seria o animal universal, aquele para quem existe o universo, se seguirmos Heidegger. Ele tem essa curiosa definição de que os seres inanimados não têm mundo, os seres animados, mas não humanos, são pobres em mundo e o homem é um ser
Incapaz de pensar a natureza obrigou-nos a demonstrar que "o homem é medida de todas as coisas" e dissolver-se na nova forma sofística praticada pelas ciências humanas e sociais. ${ }^{41}$

O objetivo de combinar aqui produçóes vindas de distintos campos do conhecimento, como a astrofísica, foi o de sugerir que um movimento de aproximação das consideraçôes produzidas dentro da filologia em direção às ciências ditas exatas pode ser a consequência mais adequada aos limites observados em nossa área. ${ }^{42}$ Como a psicanálise, a filologia deu conta de compreender um ordenamento narrativo mestre de um mundo (a tradição mimética expressa em Auerbach) e disto retirar sua exaustão, sustentada ao mesmo tempo por um excesso e uma ausência de sentido. ${ }^{43}$ Daí a aposta contemporânea, anacrônica, na aisthesis em detrimento de mimesis. A relação estabelecida por Antelo entre aisthesis e audio, e daí a evocação de Oswald de Andrade, nos traz a questão: o que ouve aquele que escreve? Se a resposta a esta pergunta for em primeiro lugar a antropogênese, ou algo como uma antropurgência, retornaremos inevitavelmente ao muçulmano de Auschwitz.

Devemos, portanto, insistir nisto: ouve o mundo.

Aquilo que a teoria da gravidade emergente (o significante é decisivo) de Erik Verlinde nos sugere é que o imaterial, o sensível ou fantasmático, podem entreter com a matéria uma relação absolutamente essencial para a segunda, ao ponto de permitir seu agrupamento e, consequentemente, sua vida. A gravidade é, para todos os efeitos, a única pulsão de vida, a verdadeira força erótica que "mantém unido tudo o que vive". ${ }^{44}$ A sugestão de que tal força venha a emergir a partir da distribuição de imagens numa tela é revolucionária principalmente por abolir a noção orbital arcaica de que tudo sempre gira em torno de algo maior e mais pesado que si (protocolo que parece abrir espaço para a plutocracia).

Assim, a literatura, ainda que se consagrando inorgânica e imaterial, não pode se dizer totalmente irresponsável para com relação a organização da máteria e dos corpos. A própria relação de organicidade ${ }^{45}$ é mais complexa do que a contemporânea renúncia obscurantista a todo e qualquer saber biológico (todo e qualquer darwinismo fascista) a vê. Em seu artigo de 1982, Stephen Jay Gould e Elisabeth Vrba introduzem, no campo das ciências biológicas, o conceito de exaptação para dar conta de características fenotípicas especiais que, embora permitissem um atual uso prático, não teriam sido construídas segundo o processo de adaptação à seleção natural:

If we ever find a small running dinosaur, ancestral to birds and clothed with feathers, we will know that early feathers were 
exaptations, not adaptations, for flight. [...] We see, in this scenario, a sequential set of adaptations, each converted to an exaptation of different effect that sets the basis for a subsequent adaptation. By this interplay, a major evolutionary transformation occurs that probably could not have arisen by purely increasing adaptation. Thus, the basic design of feather is an adaptation for thermoregulation and, later, an exaptation for catching insects. The development of large contour feathers and their arrangement on the arm arise as adaptations for insect catching and become exaptations for flight. ${ }^{46}$

O processo evolutivo descrito por Gould diz, primariamente, da qualidade bricolante da vida no mundo, num imprevisível jogo de potências no qual o intuito consciente visa aprimorar um determinado feito e logo se vê na possibilidade de fazer outra coisa daquele órgão. As penas existentes nos dinossauros de gênero Archaeopteryx continham em si a potência do vôo, mas a regulagem térmica era seu uso prático, “consciente". O ruinólogo que venha a traçar, a contracorrente, a lira deixada pela genealogia da conquista dos céus pelas aves há de se deparar, antes de tudo, com uma gritante contingência, ao ver no rastejante dinossauro um mundo por vir. Entretanto, esta fortuidade ainda assim conecta-se anatomicamente aos processos vitais que lhe antevêm, ela é desregrada consequência onírica de um desejo não menos simples: o de manter-se vivo, o de estar vivo. ${ }^{47}$

A proposta, como dito anteriormente, seria a de enxergar o objeu imagético que funda a literatura em um domínio para além do humano: ver a literatura na emergência do mundo. ${ }^{48}$ Como fala o xamá yanomami Davi Kopenawa, citado no artigo "A Floresta de Cristal" de Viveiros de Castro:

Os espíritos xapiripë dançam juntos sobre grandes espelhos que descem do céu. Nunca são cinzentos como os humanos. [...] Dá alegria de ver como são bonitos! Os espíritos são assim tão numerosos porque eles são as imagens dos animais da floresta. Todos na floresta têm uma imagem: quem anda no chão, quem anda nas árvores, quem tem asas, quem mora na água... São estas imagens que os xamãs chamam e fazem descer para virar espíritos xapiripë. Estas imagens são o verdadeiro centro, o verdadeiro interior da floresta. [...] São elas que nos fazem ver e conhecer as coisas de longe, as coisas dos antigos. Deste modo, quem não bebe o sopro dos espíritos tem o pensamento curto e enfumaçado; quem não é olhado pelos xapiripë não sonha, só dorme como um machado no chão. ${ }^{49}$

Se todo corpo pode conter ou receber um sensível, uma imagem, é ilógico determinar que a dança imagética consiste em um monopólio comportamental do humano. As plantas, o tipo de vida que mais contribui para a rico em mundo. Heidegger tem uma frase famosa que diz: "Nem mesmo a cotovia vê a clareira”. A clareira é essa abertura, o abismo sobre o qual o homem se debruça. Eu sempre achei curioso como Heidegger sabia que a cotovia náo via a clareira. Somos levados a suspeitar que os humanos não ocidentais são apenas remediados em mundo. Porque ricos em mundo mesmo, só nós. Nós somos os humanos acabados, os milionários em mundo, os acumuladores de mundo, ou, para usar a expressão de Heidegger, os configuradores de mundo. Estranha maneira de se depreciar" (VIVEIROS DE CASTRO, Eduardo. "O anti-Narciso: lugar e função da antropologia no mundo contemporâneo". Revista brasileira de psicanálise, Vol. 44, no 4, 2010, p. 16).

40 Fabián Ludueña introduz sua brilhante reflexão sobre a eugenia e a zoopolítica no primeiro livro de sua série Comunidade dos Espectros, Antropotecnia, com a seguinte provocação: "É possível reconsiderar completamente as bases sobre as quais tanto Foucault quanto Agamben pensaram a antiga política da vida sobre a base do "poder de vida e de morte"? Existe um modo de reconciliar a análise jurídica da biopolítica que faça desta uma forma do poder já presente nos inícios mesmos da civilização ocidental, e, ao mesmo tempo, respeitar a premissa do descobrimento foucaultiano, isto é, que toda biopolítica, para ser verdadeiramente tal, tem que explicar ao mesmo tempo a capacidade do poder para fazer viver e deixar morrer? Para isso, devemos abandonar o Homo sacer como paradigma da biopolítica ocidental, dado que, sob esta perspectiva, ele só pode explicar a tanatopolítica; mas devemos questionar também a suposta modernidade da biopolítica defendida por Foucault, o qual estima que, nas sociedades antigas, não se podia encontrar algo como um "fazer viver e deixar morrer” (LUDUEÑA, Fabián. A comunidade dos espectros: $I$. Antropotecnia, 2012, p. 43).

41 COCCIA, Emanuele. "Mente e matéria ou a vida das plantas". Revista Landa, v.1, n. 2, 2013. p. 197-199.

42 Como escreve Antelo: "É jus- 
tamente na eterna hesitação entre análise genética ou estrutural, explicação ou compreensão, semiótico ou semântico, que Foucault aborda a existência, para a crítica, de duas espécies de modelos: o dos conceitos vindos de outro domínio do conhecimento e que, desprovidos de eficácia operatória desempenham tão somente um papel de imagem (por exemplo, as metáforas organicistas no cosmopolitismo de Joseph Texte) e, junto a eles, os modelos constituintes tomados de empréstimo da biologia, da economia e do estudo da linguagem, como os de Araripe Jr. ou Garcia Mérou, que não são simples técnicas de formalização, mas autênticos fatores ativos para a criação de objetos de um saber possível, que desempenham o papel de categoria na prática singular da crítica” (ANTELO, Raul. A ruinologia, 2016, p. 30-1). Náo por acaso o exemplo trazido no presente artigo quanto a questáo do aglomerado de Coma Berenices, retirado de um livro de nome Origens, escrito pelo célebre diretor do Hayden Planetarium, Neil Degrasse Tyson, vem atrelado a questáo do vórtice trabalhado por Antelo na parte final de sua Ruinologia. A comprovaçáo muito recente de que um estrondoso número de galáxias de idade semelhante náo se organiza de maneira espiral refutou a principal observação de Edwin Hubble, proposta em 1923 no seu Realm of the nebulae: a de que o formato elíptico-espiralado (o vórtice) seria a forma-mestre de toda organização galáctica (DEGRASSE TYSON, Neil; GOLDSMITH, Donald. Origens: catorze bilhóes de anos de evoluçáo cósmica, 2015, p. 118).

43 Escreve Jean-Luc Nancy, em El sentido del mundo: Esta afirmación - el sentido más allá de todo sentido, el sentido en la ausencia de sentido, el desbordamiento del sentido en cuanto elemento del mundo o el mundo como exceso absoluto de sentido -, puede ser juzgada trágica, puede ser juzgada cómica, puede ser juzgada sublime y/o grotesca. Se puede - se debe -, y la monumental historia de la cultura europea no está tejida de ninguna otra cosa más que de esos juicios, cuyos nombres propios son: Sófocles, Plauto, Agustín, Dante, Montaigne, Shakespeare, Pascal, Rousseau, Hölderlin, Hugo, Kafka, Joyce, Beckett. Cuando nos ponemos a pensar en estética do planeta, ${ }^{50}$ produzem espetáculos de si (as flores) com o "intuito" de atrair outros tipos de vida (pássaros e abelhas) e assim fazer sua semente ser levada mais ao longe, para que ela nasça em condiçóes distintas das atuais. Por que razão a planta deseja a diferença? Não seria a intuição vegetal outra manifestação desta fundamentação vazia, mas necessariamente desejosa, da vida literária, dessa urgência em polinizar o ambiente com imagens distintas, que falam de um espaço ainda por emergir?

Eis o tipo de questionamento a silenciar, caso desejemos nos manter dormindo como machados no chão da tanatopolítica.

\section{Referências}

AGAMBEN, Giorgio. Homo Sacer: o poder soberano e a vida nua I. Traduçáo: Henrique Burigo. Belo Horizonte: Ed. da UFMG, 2012.

Infância e história: destruição da experiência e origem da história. Tradução: Henrique Burigo. Belo Horizonte: Ed. da UFMG, 2005.

O que é o contemporâneo? e outros ensaios. Tradução: Vinícius Nicastro Honesko. Chapecó, SC: ARGOS, 2009.

O que resta de Auschwitz. Tradução: Selvino J. Assmann. São Paulo: Boitempo Editorial, 2008.

Profanações. Tradução: Selvino J. Assmann. São Paulo: Boitempo, 2007.

A linguagem e a morte: um seminário sobre o lugar da negatividade. Tradução: Henrique Burigo. Belo Horizonte: UFMG, 2006.

ALLOA, Emmanuel [Org]. Pensar a imagem. Traduçâo: Carla Rodrigues (coordenação), Fernando Fragozo, Alice Serra e Marianna Poyares. Belo Horizonte: Autêntica, 2015.

ANTELO, Raul. A ruinologia. Florianópolis: Cultura e Barbárie, 2016.

BATAILlE, Georges. A experiência interior. Trad. Fernando Scheibe, Belo Horizonte: Autêntica, 2016.

A literatura e o mal. Trad. Fernando Scheibe, Belo Horizonte: Autêntica, 2015.

BENJAMIN, Walter. Magia e técnica, arte e política: ensaios sobre literatura e história da cultura. Tradução: Sergio Paulo Rouanet. São Paulo: Brasiliense, 1987.

COCCIA, Emanuele. A vida sensivel. Trad. Diego Cervelin, Florianópolis: Cultura e Barbárie, 2010. 
"Mente e matéria ou a vida das plantas". Trad. Nicoletta Cherobin. Revista Landa. Vol. 1, no 2, 2013, p. 197-220.

DEGRASSE TYSON, Neil; GOLDSMITH, Donald. Origens: catorze bilhóes de anos de evolução cósmica. Trad. Rosaura Eichenberg, São Paulo: Planeta do Brasil, 2015.

DELEUZE, Gilles; GUATTARI, Félix. O anti-Édipo, Trad. Luiz B. L. Orlandi. São Paulo: Editora 34, 2011.

DUNKER, Christian Ingo Lenz. Mal-estar, sofrimento e sintoma: uma psicopatologia do Brasil entre muros. São Paulo: Boitempo Editorial, 2015.

DARWIN, Charles. The origin of species. London: Collector's Library, 2004.

FREUD, Sigmund. História de uma neurose infantil: "O homem dos lobos", além do princípio do prazer e outros textos (1917-1920). Tradução: Paulo César de Souza. São Paulo: Companhia das Letras, 2010.

GAGNEBIN, Jeane Marie. “Apresentação”. In: AGAMBEN, Giorgio. O que resta de Auschwitz? São Paulo: Boitempo Editorial, 2008, p. 9-17.

GOULD, Stephen Jay; VRBA, Elisabeth S. "Exaptation: a missing term in the science of form”. Paleobiology Magazine, Vol. 8, no 1, 1982, p. 4-15.

HAMACHER, Werner. 95 tesis sobre la filología. Trad. Laura S. Carugati. Buenos Aires: Mino y D’Ávila, 2011.

HOBBES, Thomas. Leviatã, ou matéria, forma e poder de um estado eclesiástico e civil. Trad. Daniel Moreira Miranda. São Paulo: EDIPRO, 2015.

LACAN, Jacques. "Função e campo da fala e da linguagem”. In: Escritos.

Trad. Vera Ribeiro. Rio de Janeiro: Zahar, 1998, p. 238-324.

"A instância da letra no inconsciente ou a razão desde Freud". In:

Escritos. Trad. Vera Ribeiro. Rio de Janeiro: Zahar, 1998, p. 496-536.

O Seminário: Livro 7, A Ética da Psicanálise. Tradução: Antônio Quinet.

São Paulo: Jorge Zahar, 2008.

LUDUEÑA, Fabián. A comunidade dos espectros: I. Antropotecnia. Trad. Alexandre Nodari, Leonardo D’Ávila. Florianópolis: Cultura e Barbárie, 2012.

NANCY, Jean-Luc. El Sentido Del Mundo. Trad. Jorge Manuel Casas. Buenos Aires: la marca editora, 1993.

RANCIÈRE, Jacques. O destino das Imagens. Tradução: Mônica Costa Netto. Rio de Janeiro: Contraponto, 2012. ello nos encontramos con que lo que Europa tuvo de más genial, y quizá su idea misma del genio, surgió ante todo a partir de una formidable necesidad de poner en escena el sentido del sentido, de figurarlo, de agitar sus máscaras, sus destellos, sus trayectorias, en una dramatización intensa cuyo recurso es Occidente mismo en tanto oscurecimiento originario del sentido: interrupción del mito y del sacrificio, que se convierte en aquello que Occidente sólo puede mimar (es lo que dice de sí mismo)" (NANCY, Jean-Luc. El Sentido Del Mundo, 1993, p. 43).

44 FREUD, Sigmund. Além do princípio do prazer, [1920] 2010, p. 160.

45 Do grego, órganon: instrumento.

46 GOULD, Stephen Jay; VRBA, Elisabeth S. "Exaptation: a missing term in the science of form". Paleobiology Magazine, v.8, n.1, 1982, p. 7-8.

$47 \mathrm{Um}$ argumento similar quanto ao psiquismo, em defesa da bricolagem e em renúncia ao neuróticocentrismo da clínica psicanalítica, aparece em 1972 com O Anti-Édipo.

48 Nancy, outra vez: "Incluso se lo puede decir así: en tanto el mundo estaba esencialmente en referencia con lo otro (con un otro mundo o con un autor del mundo) podía tener un sentido. Pero el fin del mundo consiste en que ya no hay más esta referencia esencial, y que esencialmente (es decir, existencialmente) ya no hay más que el mundo 'mismo'. Entonces, el mundo no tiene más sentido, pero es el sentido" (NANCY, JeanLuc. El Sentido Del Mundo, 1993, p. 23).

49 Davi Kopenawa, apud. VIVEIROS DE CASTRO, Eduardo. "A floresta de cristal: notas sobre a ontologia dos espíritos amazônicos". Cadernos de campo, no14/15, p. 320.

50 COCCIA, Emanuele. "Mente e matéria ou a vida das plantas". Revista Landa, v.1, n. 2, 2013. p. 211. 
VERLINDE, Erik. On the origin of gravity and the laws of Newton. Ithaca: Cornell University Library, 2010. Disponível em: https://arxiv.org/abs/1001.0785

Emergent gravity and the dark universe. Ithaca: Cornell University Library, 2016. Disponível em: https://arxiv.org/abs/1611.02269

VIVEIROS DE CASTRO, Eduardo. "A floresta de cristal: notas sobre a ontologia dos espíritos amazônicos”. Cadernos de campo, São Paulo, no14/15, p. 319-338.

"O anti-Narciso: lugar e função da antropologia no mundo contemporâneo”. Revista brasileira de psicanálise, Vol. 44, no 4, 2010, p. 15-26.

WARBURG, Aby. Histórias de fantasma para gente grande: escritos, esboços e conferências. Org.: Leopoldo Waizbort. Trad. Lenin Bicudo Bárbara. São Paulo: Companhia das Letras, 2015.

ŽIŽEK, Slavoj. Alguém disse totalitarismo? Cinco intervenções no (mau) uso de uma noção. Tradução: Rogério Bettoni. São Paulo: Boitempo Editorial, 2013. 